\title{
Management of Le Fort I fracture
}

\author{
Hak Su Kim, \\ Seong Eun Kim, \\ Hyun Tae Lee
}

Department of Plastic and Reconstructive Surgery, Pohang Semyeong Christianity Hospital, Pohang, Korea

No potential conflict of interest relevant to this article was reported.

\begin{abstract}
Among the classification of maxillary fracture, the Le Fort classification is the best-known categorization. Le Fort (1901) completed experiments that determined the maxilla areas of structural weakness which he designated as the "lines of weakness". According to these results, there are three basic fracture line patterns (transverse, pyramidal and craniofacial disjunction). A transverse fracture is a Le Fort I fracture that is above the level of the apices of the maxillary teeth section, including the entire alveolar process of the maxilla, vault of the palate and inferior ends of the pterygoid processes in a single block from the upper craniofacial skeleton. Le Fort fractures result in both a cosmetic and a functional deficit if treated inappropriately. In this article, authors review the management of a Le Fort I fracture with a case-based discussion.
\end{abstract}

Keywords: Fractures / Maxillary / Review

\section{INTRODUCTION}

Rene Le Fort's seminal classification system for maxillary fractures has been the standard for over 100 years. This system was developed through direct observation, and incorporates what Le Fort described as "great weak lines" in the craniofacial skeleton [1]. Le Fort found three basic patterns of maxillary fracture lines: transverse, pyramidal and craniofacial disjunction (Fig. 1). The transverse fracture is the Le Fort I fracture through the maxilla, cephalic to the maxillary dentition.

The symptoms of a Le Fort I fracture include swelling of the midface, a profuse nasopharyngeal bleeding, pain, malocclusion, and intraoral laceration. Fcacial elongation and facial retrusion can occur if the patient is not placed in intermaxillary fixation (IMF) and the midface is allowed to displace. The maxillary alveolus is usually retruded, and tilts with premature contact with the mandible in the molar occlusion [2]. In this review, authors provide the case of management of a Le Fort I fracture.

Correspondence: Hak-Su Kim

Department of Plastic and Reconstructive Surgery, Pohang Semyeong Christianity Hospital, 351 Posco-daero, Nam-gu, Pohang 37816, Korea

E-mail: pskimhs@hanmail.net

*This paper was presented at 2016 spring symposium of Korean Cleft Palate-

Craniofacial Association (23rd/April/2016).

Received August 18, 2016 / Revised March 4, 2017 / Accepted March 4, 2017

\section{STRUCTURES INVOLVED}

Bones fractured in a Le Fort I fracture include the lower nasal septum, the inferior portion of the pyriform apertures, the canine fossae, both zygomaticomaxillary buttresses, the posterior maxillary walls, and the pterygoid plates. The most consistent and uniting feature of a Le Fort fracture is the presence of bilateral pterygoid fractures. Pterygoid fractures are found in all three classes of Le Fort fractures, and are the key to establishing the diagnosis. If a computed tomography (CT) reveals bilateral pterygoid fractures, a Le Fort fracture should be suspected. Conversely, if the CT scan does not reveal pterygoid fractures, the Le Fort fractures can be excluded [3]. However, the fracture of the pterygoid plate is not limited to Le Fort fractures. A retrospective review of CT scans obtained on craniofacial trauma patients over a 5 -year period revealed 209 patients with pterygoid plate fractures. Pterygoid plate fractures in 78 patients (37.3\%) were unrelated to Le Fort fractures. Common causes included sphenotemporal buttress fractures in 26 patients (33.3\%), temporal bone fractures in 18 patients (23.1\%), zygomaticomaxillary complex fractures in 17 patients $(21.8 \%)$, and displaced mandible fractures in 14 patients (17.9\%). These findings indicate that approximately one third of pterygoid plate fractures do not result from Le Fort pattern injuries and that the 

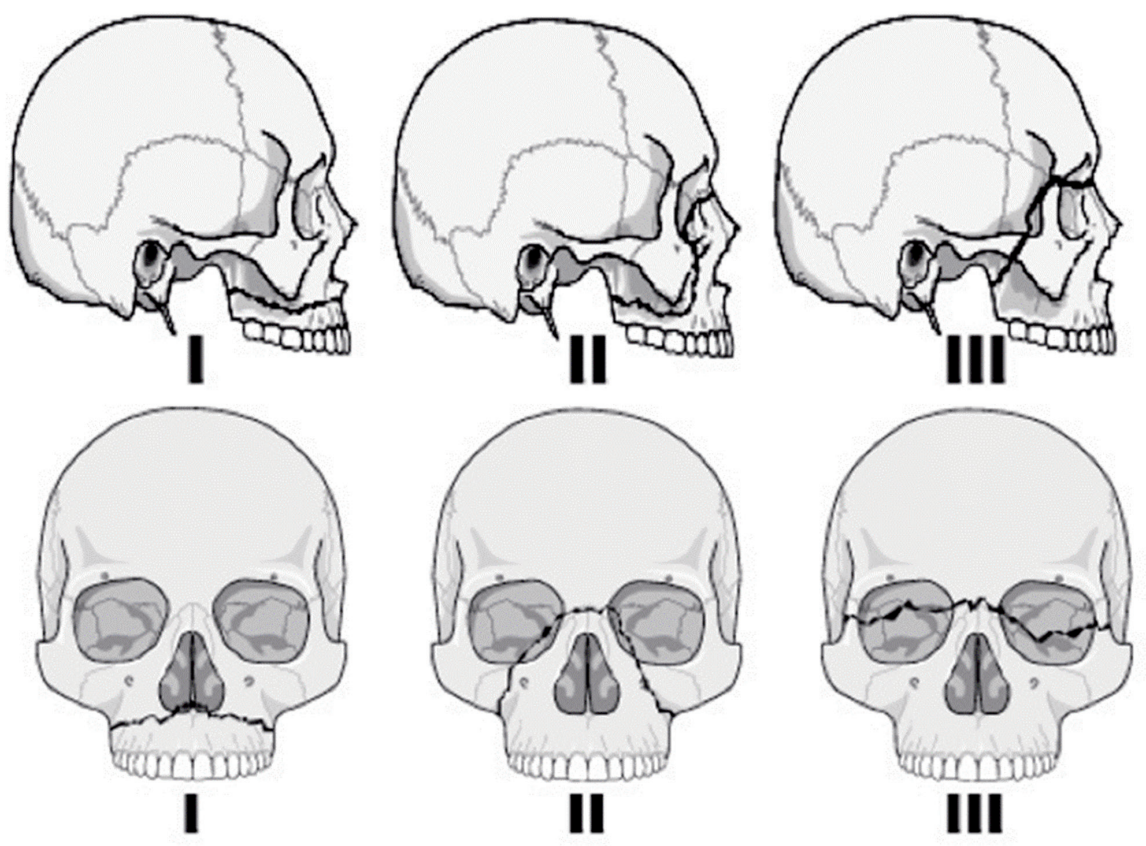

Fig. 1. Classical Le Fort Fracture pattern line diagrams.

craniofacial surgeon should have a broad differential for causes of pterygoid plate fractures when reviewing trauma imaging [4].

Among Le Fort fractures, only the Le Fort I fracture involves the lateral aspect of the pyriform aperture. Therefore, the absence of a lateral pyriform fracture rules out a Le Fort I fracture.

\section{TREATMENT}

The goals of the treatment of Le Fort I fractures are to restore midfacial height and projection and to reestablish pre-traumatic occlusal relationships. The structural support between the areas of the buttress and maxillary alveolus must also be restored to provide for proper soft tissue contour [5].

Le Fort I fractures may be accessed by a gingivobuccal sulcus incision, and fixed by reestablishing the midfacial buttresses using 1.5 to $2.0 \mathrm{~mm} \mathrm{~L}$ and J plates. To prevent the forces of mastication from disrupting the repair, emphasis must be put on placing the plates in the same direction as the forces of mastication [6]. The most common disturbance in a treated Le Fort injury is reduced midfacial height and projection rather than the facial elongation and retrusion seen in an untreated Le Fort fracture. It becomes important, therefore, to restore the facial height and projection by anatomic reconstruction of the buttresses of the maxilla. Anteriorly, nasomaxillary and zygomaticomaxillary buttresses are reconstructed after alignment, providing bone grafts and rigid fixation for stability. The fracture is usually worse on one side. The more intact side is often the best key to the correct facial height. Correction of the posterior facial height does not involve accurate reconstruction of the pterygoid buttresses, but is achieved by IMF [5].

Author present the case who diagnosed Le Fort I fracture. A 53-year-old man presented to our clinic with an injury from falling down from a height of $3 \mathrm{~m}$. Clinical signs and symptoms demonstrated painful upper lip and cheek swelling, subcutaneous emphysema, epistaxis, chin abrasion, oral mucosal laceration and malocclusion.

Computed tomography (CT) showed the fracture of both zygomaticomaxillary buttresses, the inferior portion of the piriform apertures, the lower nasal septum, the posterior maxillary walls, and both pterygoid plates, which indicates a Le Fort I fracture (Fig. $2 \mathrm{~A}, \mathrm{~B})$. 

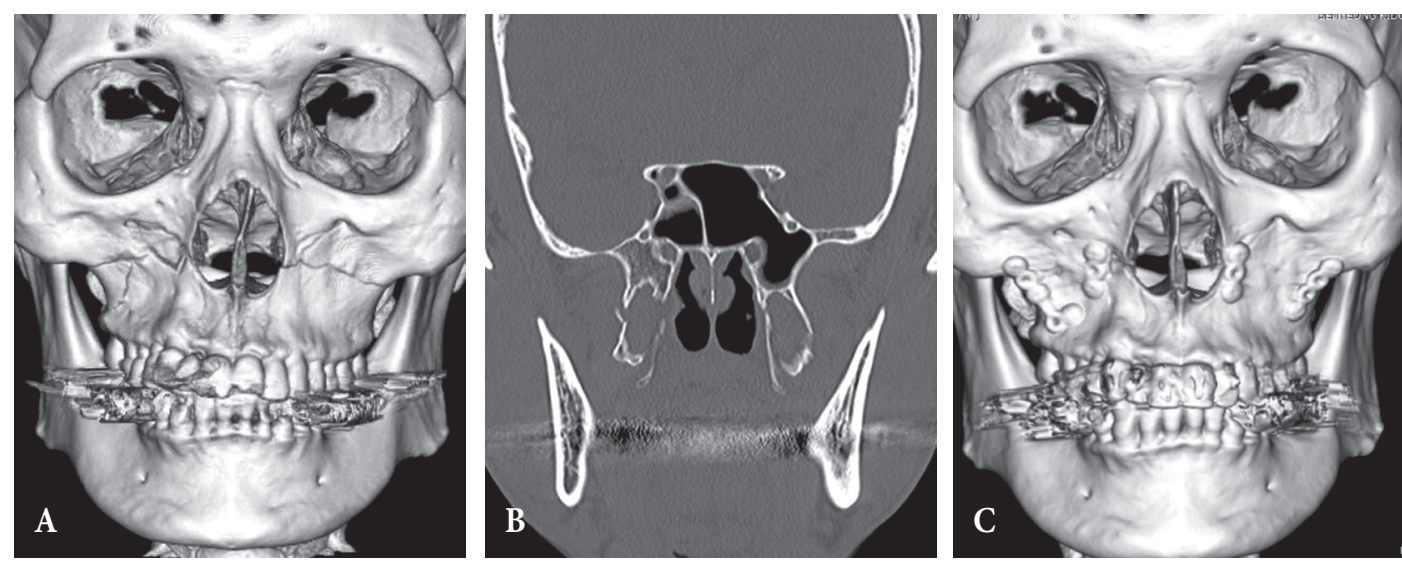

Fig. 2. (A) Preoperative computed tomography (CT) showed a Le Fort I fracture. (B) Fracture of both pterygoid plates. (C) Postoperative CT 3.5 months after the surgery.

Prophylactic systemic antibiotics were administered to reduce the chances of cheek cellulitis. Open reduction and internal fixation, with mini-plates and screws, were performed eight days after injury. Simultaneously, the IMF was performed using dual-top screws. The plates and screws fixed both the zygomaticomaxillary buttress and piriform aperture. A postoperative CT was taken several months after the surgery and demonstrated adequate reduction of the displaced maxilla with neutrocclusion (Fig. 2C). The total hospital stay was 13 days.

\section{VARIABLES AFFECTING TREATMENT}

Review of preoperative and postoperative CT scans and clinical examinations demonstrates the most common errors with regard to midface fracture treatment. Commonly, patients released from IMF early and patients having late fracture reduction (where IMF was placed late after the initial injury) would be observed to have a small anterior open bite after the release of IMF. The majority of highly comminuted fractures treated with immediate release of IMF (62\%) had to be managed with traction elastics or a reinstitution of IMF. Lack of cuspid contact and incisor separation are the first signs of an open bite. When maxillary fractures were placed into IMF late, the maxilla, at its third (pterygoid) buttress, descended inferiorly and posteriorly. Posterior maxillary buttress elongation may also be permitted by early release of IMF and is increased by elastic traction applied to the posterior dentition.
There is tendency in Le Fort fractures for the maxilla to be anteriorly displaced and impacted. When anteriorly displaced and impacted or when partially healed, maxillary fractures placed in IMF, without a complete mobilization and repositioning of the maxilla, allow the mandibular condyle to easily move anteriorly into the glenoid fossa to permit occlusal contact of the mandible with an impacted, malpositioned maxilla. When the IMF is released, the mandible moves posteriorly to re-set itself in its normal glenoid fossa position; however, the maxilla remains displaced, producing a class II occlusion and an anterior open bite [7].

\section{CONCLUSION}

Among the several kinds of classifications of maxillary fractures, the Le Fort classification system is widely known, and provides a method for concise communication of fracture patterns between clinicians and radiologists. A thorough understanding of the facial skeleton is essential for proper diagnosis and treatment of Le Fort fractures, to prevent cosmetic and functional deformities.

\section{REFERENCES}

1. Tessier P. The classic reprint: experimental study of fractures of the upper jaw. 3. Rene Le Fort, M.D., Lille, France. Plast Reconstr Surg 1972;50:600-7.

2. Manson PN. Facial fractures. In: Aston SJ, Grabb WC, editors. Grabb and Smith's plastic surgery. New York: Lippincott-Raven; 1997. p.398- 
401.

3. Fraioli RE, Branstetter BF 4th, Deleyiannis FW. Facial fractures: beyond Le Fort. Otolaryngol Clin North Am 2008;41:51-76.

4. Garg RK, Alsheik NH, Afifi AM, Gentry LR. Pterygoid plate fractures: not limited to Le Fort fractures. J Craniofac Surg 2015;26:1823-5.

5. Manson PN. Facial fractures. In: Mathes SJ, Hentz VR, editors. Plastic surgery. Vol. VIII. Philadelphia, PA: Saunders Elsevier; 2006. p. 229-55.
6. Kochhar A, Byrne PJ. Surgical management of complex midfacial fractures. Otolaryngol Clin North Am 2013;46:759-78.

7. Manson PN, Clark N, Robertson B, Slezak S, Wheatly M, Vander Kolk $\mathrm{C}$, et al. Subunit principles in midface fractures: the importance of sagittal buttresses, soft-tissue reductions, and sequencing treatment of segmental fractures. Plast Reconstr Surg 1999;103:1287-306. 